\title{
Menadione effect on L-cysteine desulfuration in U373 cells
}

\author{
Maria Wróbel ${ }^{\bowtie}$ and Halina Jurkowska \\ Chair of Medical Biochemistry, Jagiellonian University Medical College, Kraków, Poland
}

Received: 13 March, 2007; revised: 30 March, 2007; accepted: 16 April, 2007

available on-line: 23 May, 2007

\begin{abstract}
The non-cytotoxic concentration $(20 \mu \mathrm{M})$ of menadione (2-methyl-1,4-naphthoquinone), after $1 \mathrm{~h}$ of incubation, leads to loss of the activity of rhodanese by 33\%, 3-mercaptopyruvate sulfurtransferase by $20 \%$, as well as the level of sulfane sulfur by about $23 \%$ and glutathione by $12 \%$, in the culture of U373 cells, in comparison with the control culture. Reactive oxygen species generated by menadione oxidize sulfhydryl groups in active centers of the investigated enzymes, inhibiting them and saving cysteine for glutathione synthesis. A decreased sulfane sulfur level can be correlated with an oxidative stress.
\end{abstract}

Keywords: astrocytoma U373, menadione, 3-mercaptopyruvate sulfurtransferase, reactive oxygen species, rhodanese, sulfane sulfur

\section{INTRODUCTION}

3-Mercaptopyruvate sulfurtransferase (MPST, EC 2.8.1.2), one of two enzymes generating sulfane sulfur-containing compounds from $\mathrm{L}$-cysteine (Scheme 1), plays the main role in astrocytoma U373 cells because of the very low levels of $\gamma$-cystathionase (cystathionine $\gamma$-lyase, EC 4.4.1.1) activity (Jurkowska \& Wróbel, 2007). Rhodanese (thiosulfate sulfurtransferase, EC 2.8.1.1) is a well-known enzyme participating in transferring labile sulfur atoms from various sulfane sulfur-containing compounds to various acceptors (Westley et al., 1983). Sulfane sulfur atoms are provided for the synthesis of iron sulfur proteins and for detoxification of such compounds as, for example, cyanide (Westley, 1973; 1980; Beinert, 2000; Liew \& Shaw, 2005). The antioxidant potential of sulfane sulfur and rhodanese has also been demonstrated (Ogasawara et al., 1999; Nandi et al., 2000; Wróbel et al., 2004).

MPST and rhodanese are members of the same family (Nagahara, 1995). The catalytic site of both enzymes contains a Cys247 residue, which is proposed to form persulfide in the process of catalysis (Nagahara \& Nishino, 1996). Enzymes containing catalytic cysteines are generally inhibited by hydrogen peroxide (Cannella \& Berni, 1983; Lee et al., 1998; Skorey et al., 1997). Under these oxidizing conditions, formation of a sulfenate $\left(-\mathrm{SO}^{-}\right)$, a sulfinate $\left(-\mathrm{SO}_{2}^{-}\right)$, a sulfonate $\left(-\mathrm{SO}_{3}^{-}\right)$, a sulfenyl compound $(-\mathrm{S}-\mathrm{R})$, or a disulfide bond has been characterized (Poole \& Claiborne 1989; Claiborne et al., 1999). Mild oxidation of MPST was found to result in formation of a stable sulfenate $\left(-\mathrm{SO}^{-}\right)$at $\mathrm{Cys} 247$, which exhibits lower redox potential than that of glutathione (Nagahara \& Katayama, 2005). Oxidative stress decreases the MPST activity so as to increase the amount of cysteine (Scheme 1), a precursor of glutathione, and furthermore, these cellular reductants restore this activity. Thus, the redox state regulates the MPST activity at the enzymatic level, and on the other hand, MPST helps maintain cellular redox homeostasis.

The cytotoxic effects of menadione (vitamin K-3, 2-methyl-1,4-naphthoquinone) are thought to be mediated through its one-electron reduction to semiquinone radicals, which subsequently enter redox

${ }^{\square}$ Corresponding author: M. Wróbel, Jagiellonian University Medical College, Chair of Medical Biochemistry, M. Kopernika 7, 31-034 Kraków, Poland; phone: (48 12) 424 7229; fax: (48 12) 422 3272; e-mail: mbwrobel@cyf-kr.edu.pl

Abbreviations: DMEM, Dulbecco's modified eagle medium; DTNB, 5,5'-dithio-bis-(2-nitrobenzoic acid); DTT, DL-dithiothreitol; LDH, lactate dehydrogenase; MPST, 3-mercaptopyruvate sulfurtransferase; NEM, N-ethylmaleimide; PBS, potassium phosphate buffer containing $150 \mathrm{mM} \mathrm{NaCl}$; PLP, pyridoxal phosphate; ROS, reactive oxygen species. 


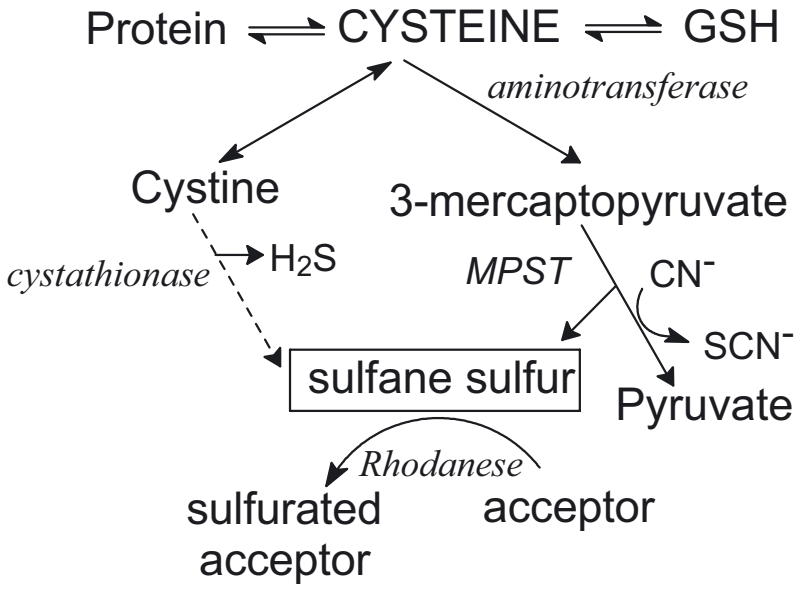

Scheme 1. Sulfane sulfur formation from L-cysteine. In U373 cells, MPST playes the main role in generating sulfane sulfur-containing compounds from L-cysteine because of trace activity of $\gamma$-cystathionase (dotted line).

cycles with molecular oxygen to produce reactive oxygen species and oxidative stress. The cytotoxicity of menadione seems to be associated with superoxide generation, protein thiol oxidation, and alteration in the $\mathrm{Ca}^{2+}$ homeostasis (DiMonte et al., 1984a; 1984b; Niemczyk et al., 2004). Menadione may cause toxicity due to depletion of glutathione by conjugate formation (2-methyl-3-glutathionyl-1,4-naphthoquinone is a product of direct reaction of glutathione with menadione) (Wefers \& Sies, 1983; Mauzeroll \& Bard, 2004).

In this study, we provide evidence that both investigated sulfurtransferases, rhodanese and MPST, have lower activity in U373 cells in the presence of menadione in the culture medium, probably due to oxidation of the $-\mathrm{SH}$ group of their catalytic cysteines. In effect, cysteine conversion to sulfane sulfur compounds is slower and the amount of cysteine available for the synthesis of glutathione is higher (Scheme 1).

\section{MATERIALS AND METHODS}

Sources of chemicals. Folin-Ciocalteau reagent, NADPH $\left(\mathrm{Na}_{4}\right)$, NADH, 5,5'-dithio-bis-(2-nitrobenzoic acid) (DTNB), glutathione reductase, lactate dehydrogenase (LDH), pyridoxal phosphate (PLP), DL-dithiothreitol (DTT), N-ethylmaleimide (NEM), trypsin, menadione sodium bisulfite, DMEM (Dulbecco's modified Eagle medium) were obtained from Sigma Chemical Company (St. Louis, MO, USA). Fetal bovine serum was obtained from Gibco Laboratories (Grand Island, NY, USA), potassium cyanide from Merck (Darmstadt, Germany), sodium 3mercaptopyruvate from Flucka Chemie GmbH. The Cytotoxicity Detection Kit (LDH) and Cell Prolifera- tion ELISA, BrdU (colorimetric) test were obtained from Roche Applied Science. All other chemicals were of reagent grade and purchased from common commercial suppliers.

Cell culture. All experiments were performed using the human astrocytoma U373 cell line. U373 cells were grown in monolayer in DMEM supplemented with $10 \%$ fetal bovine serum and antibiotics (100 U/ml penicillin and $100 \mu \mathrm{g} / \mathrm{ml}$ streptomycin), in plastic culture dishes $\left(100 \mathrm{~mm}\right.$ in diameter), at $37^{\circ} \mathrm{C}$, in a humidified atmosphere containing $5 \% \mathrm{CO}_{2}$. After trypsinization $(0.25 \%$ trypsin/EDTA), the cells were diluted with complete medium (DMEM with 10\% FBS) (Ponten \& Macintyre, 1968).

Treatment of cells with menadione. The cells were seeded at $1 \mathrm{mln} / 100 \mathrm{~mm}$ dish the day before treatment. Menadione $(5-50 \mu \mathrm{M})$ was dissolved in cell culture media and filtered through a $0.22-\mu \mathrm{m}$ filter for sterilization. The cells were incubated for 1 or $5 \mathrm{~h}$ and then washed three times with $3 \mathrm{ml}$ of PBS (10 mM potassium phosphate buffer, $\mathrm{pH}$ 7.4, containing $150 \mathrm{mM} \mathrm{NaCl}$ ). Then the cells were harvested in cold PBS, centrifuged at 5000 r.p.m. at $4^{\circ} \mathrm{C}$ during $10 \mathrm{~min}$ and solubilized in phosphate buffer, pH 7.5 for homogenization.

Determination of cell viability. Cell viability was investigated by measuring the leakage of LDH from dead or dying cells into the culture medium using the Cytotoxicity Detection Kit. Briefly, the cells were cultured in 96-well plates at a density of $1.5-2 \times 10^{3}$ U373 cells per well. After treatment, LDH was determined spectrophotometrically by measuring its activity in an aliquot of cell-free medium. One hundred microliters of the culture medium collected from the dishes after the incubation of the cells were added to $100 \mu \mathrm{l}$ of the incubation mixture and incubated for $30 \mathrm{~min}$ at room temperature, in the dark. After the incubation, $50 \mu \mathrm{l}$ of $1 \mathrm{M} \mathrm{HCl}$ was added and the absorbance was measured with a microculture plate reader at $490 \mathrm{~nm}$. The leakage was calculated as the percentage of total activity after lysis of the cells by $1 \%$ Triton X-100.

Cell homogenization. U373 cells $\left(2-6 \times 10^{6}\right)$ were suspended in $0.1 \mathrm{M}$ phosphate buffer $\mathrm{pH} 7.5$, in the proportion $1 \mathrm{mln}$ cells $/ 0.04 \mathrm{ml}$ of the buffer, sonicated $3 \times 5 \mathrm{~s}$ at $4^{\circ} \mathrm{C}$ (Bandelin Sonoplus GM 70). After centrifugation at 3000 r.p.m. for $10 \mathrm{~min}$, the supernatant was used for the determination of protein concentration, sulfane sulfur levels and the activity of rhodanese and MPST. For glutathione determinations, the homogenate was deproteinized by adding 5\% trichloroacetic acid in the proportion 1:1 and centrifuged for $10 \mathrm{~min}$ at 3000 r.p.m.

Enzyme assays. MPST activity was assayed according to the method of Valentine and Frankelfeld (1974), following a procedure described in our earlier paper (Wróbel et al., 1997). The enzyme 
activity was expressed as nmoles of pyruvate produced during $1 \mathrm{~min}$ incubation at $37^{\circ} \mathrm{C}$ per $1 \mathrm{mg}$ of protein. Rhodanese activity was assayed by Sőrbo's method (1955), following a procedure described in Wróbel et al. (1997). The enzyme activity was expressed as nmoles $\mathrm{SCN}^{-}$formed during $1 \mathrm{~min}$ incubation at $20^{\circ} \mathrm{C}$ per $1 \mathrm{mg}$ of protein.

Sulfane sulfur was determined by the method of Wood (1987), based on cold cyanolysis and colorimetric detection of ferric thiocyanate complex ion; protein was determined by the method of Lowry et al. (1951) using crystalline bovine serum albumin as a standard, and the cellular glutathione content was determined by a modification of the enzymatic assay originally described by Tietze (1969). The Tietze method measures the rate of reduction of 5,5'-dithiobis-(2-nitrobenzoic acid) (DTNB) in the presence of glutathione reductase.

Presentation of data and statistical analysis. Each group consisted of 3-4 culture dishes per experiment for each time point studied. The experiments were performed in triplicate or quadruplicate, and the cultures were taken from 4-7 separate seedings. The data are presented as means \pm standard deviation from the individual values measured. The statistical significance was determined using the Student's $t$-test. $P<0.05$ was considered significant.

\section{RESULTS AND DISCUSSION}

\section{Menadione cytotoxicity to U373 cells}

A basal cytotoxicity test for predicting starting concentrations for the investigation of menadione effect on L-cysteine desulfuration in U373 cells showed that the viability of the cells after each time point studied ( $1 \mathrm{~h}$ and $5 \mathrm{~h}$ ) was between 92 and 100\% for 5 $\mu \mathrm{M}, 20 \mu \mathrm{M}$ and $50 \mu \mathrm{M}$ menadione concentrations in culture medium (Fig. 1). The addition of menadione to U373 cells produced a concentration- and time-dependent loss of cell viability. For cytotoxic menadi-

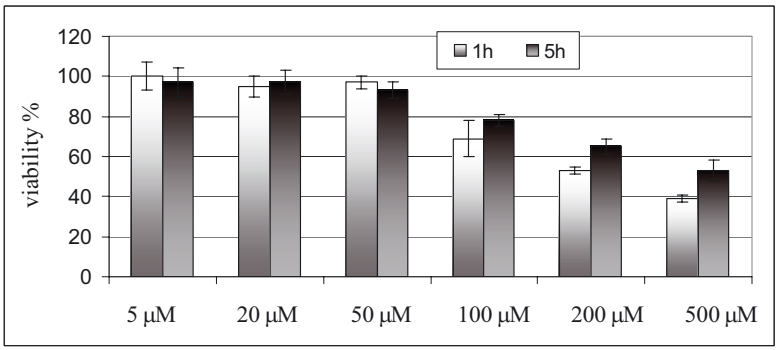

Figure 1. Menadione cytotoxicity to U373 cells.

Cell viability was investigated by measuring the leakage of LDH from cells into the culture medium. The absorbance was measured at $490 \mathrm{~nm}$. The leakage was calculated as a percentage of total activity after lysis of the cells by $1 \%$ Triton X-100.

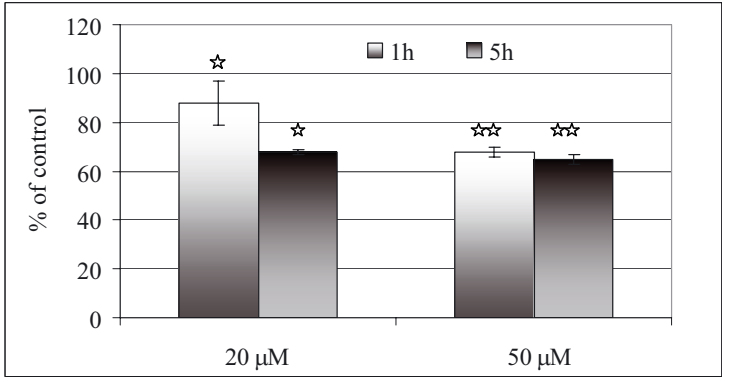

Figure 2. Menadione effect on the level of cellular glutathione.

Menadione was dissolved in cell culture media $(20 \mu \mathrm{M}$ or $50 \mu \mathrm{M})$. The cells were incubated for 1 or $5 \mathrm{~h}$, harvested in PBS and sonicated, the homogenate was deproteinized and centrifuged. Glutathione level determined in control supernatants was $25.9 \pm 2.6$ nmoles per $\mathrm{mg}$ of protein. ${ }^{*} P<0.05,{ }^{*} P<0.001$ (Student's $t$ test) $v$ s. the controls.

one concentrations $(100 \mu \mathrm{M}, 200 \mu \mathrm{M}$ and $500 \mu \mathrm{M})$, the shorter duration produced a higher cytotoxic effect, thus suggests that cells could develop some resistance to menadione and their total number somewhat increased after $5 \mathrm{~h}$ incubation. It was found for Hep G2 cells that preincubation with low, nontoxic concentrations of menadione increased the viability of the cells in the presence of toxic doses of menadione or $\mathrm{H}_{2} \mathrm{O}_{2}$ (Chen \& Cederbaum, 1997).

\section{Menadione effect on the level of cellular glutath- ione}

Menadione diffusion into cells upon addition to the extracellular media, without the assistance of transport proteins or pumps, has been reported for many different cell types, such as yeast (Mauzeroll \& Bard, 2004) or human breast cells (Liu et al., 2000). Inside the cell, menadione is rapidly conjugated to intracellular glutathione to form a stable conjugate (Mauzeroll et al., 2004) or a rapid depletion of intracellular glutathione occurs due to oxidation of glutathione which forms disulfide dimers (glutathione disulfide) (DiMonte et al., 1984b). Figure 2 shows that in U373 cells cultured in the medium containing non-cytotoxic concentrations of menadione $(20 \mu \mathrm{M}$ and $50 \mu \mathrm{M}$ ), the level of glutathione was decreased respectively by about $12 \%$ and $32 \%$ after $1 \mathrm{~h}$, and $32 \%$ and $35 \%$ after $5 \mathrm{~h}$ of incubation, in comparison with the controls. Although for both investigated time frames, the higher menadione concentration produced a higher decrease in glutathione level, it should be noted that for the $50 \mu \mathrm{M}$ concentration, the drop was not proportional to time. This effect can be explained by a higher amount of glutathione available for formation of menadione-S-conjugates or for detoxification of ROS generated by menadione. It is possible that during $5 \mathrm{~h}$ of incubation glutathione synthesis is stimulated. It was observed 


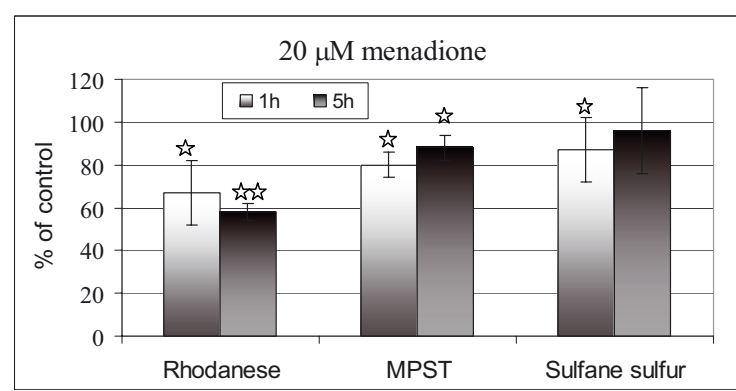

Figure 3. Menadione effect on rhodanese and MPST activity and the level of sulfane sulfur.

Menadione $(20 \mu \mathrm{M})$ was dissolved in cell culture media. The cells were incubated for 1 or $5 \mathrm{~h}$, harvested in PBS, centrifuged and resuspended in phosphate buffer, $\mathrm{pH} 7.5$ for homogenization. The activity of MPST and rhodanese

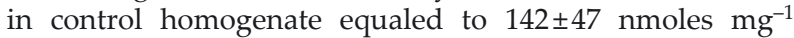
$\mathrm{min}^{-1}$ and $22 \pm 7$ nmoles $\mathrm{mg}^{-1} \mathrm{~min}^{-1}$, respectively. The level of sulfane sulfur in control homogenate was $148 \pm 26$ nmoles per $\mathrm{mg}$ of protein. ${ }^{*} P<0.05,{ }^{*} P<0.001$ (Student's $t$-test) vs. the controls.

that 2,3-dimethoxy-1,4-naphthoquinone and menadione, redox cycling quinones, increased the activity of $\gamma$-glutamylcysteine synthase in bovine pulmonary artery endothelial cells and Chinese hamster lung fibroblast V79 cells (Shi et al., 1994; Ochi, 1996). An increase of glutathione concentration in cells can be also achieved by the inhibition of cysteine-consuming pathways, which are alternatives to glutathione synthesis, e.g., sulfane sulfur formation from cysteine (Scheme 1).

\section{Menadione effect on rhodanese and MPST activity and the level of sulfane sulfur}

The activity of MPST, the main sulfane sulfur generating enzyme in U373 cells, was found to be lower by about $20 \%$ as compared with the control cells after $1 \mathrm{~h}$ of incubation with $20 \mu \mathrm{M}$ menadione in the culture medium (Fig. 3). This was associated with a decreased level of sulfane sulfur-containing compounds and a decreased value of rhodanese activity. A decreased MPST activity leads to an inhibition of cysteine conversion to sulfane sulfur and as a result, more cysteine can be driven to glutathione synthesis (Scheme 1), what was observed after $5 \mathrm{~h}$ of incubation. The activity of MPST was lower by $12 \%$ as compared with the control cells after $5 \mathrm{~h}$ of incubation, suggesting that some processes leading to the elevation of the MPST activity has started up. It is possible that an elevated level of glutathione (Fig. 2, $50 \mu \mathrm{M}$ concentration) restores the activity of the oxidized, Cys247-sulfenate $\left(-\mathrm{SO}^{-}\right)$form of the enzyme (Fig. 3, 5 h) (Nagahara \& Katayama, 2005). Similarly, the inhibition of rhodanese activity can result from the oxidation of the $-\mathrm{SH}$ group in its catalytic center by menadione-generated ROS, apart from a decreased level of sulfane sulfur-containing compounds, its donor substrates. An increased level of MPST after $5 \mathrm{~h}$ of incubation, as compared with $1 \mathrm{~h}$, was correlated with an increased level of sulfane sulfur. Such adaptive responses of U373 cells to oxidative stress due to menadione presence seem to be very important because, as it was previously found (Jurkowska \& Wróbel, 2007), a lowered level of sulfane sulfur is correlated with an increased rate of cell proliferation.

\section{REFERENCES}

Beinert H (2000) FEBS J 267: 5657-5664.

Cannella C, Berni R (1983) FEBS Lett 162: 180-184.

Chen Q, Cederbaum AI (1997) Mol Pharmacol 52: 648-657.

Claiborne A, Joanne I, Mallett TC, Luba J, Crane EJ, Charrier V, Parsonnage D (1999) Biochemistry 38: 1540715416.

DiMonte D, Bellomo H, Thor G, Nicotera P, Orrenius S (1984a) Arch Biochem Biophys 235: 343-350.

DiMonte D, Ross D, Bellomo G, Eklöw L, Orrenius S (1984b) Arch Biochem Biophys 235: 334-342.

Jurkowska H, Wróbel M (2007) Amino Acids DOI: 10.1007/ s00726-007-0471-2.

Lee SR, Kwon KS, Kim SR, Rhee SG (1998) J Biol Chem 273: 15366-15372.

Liew YF, Shaw NS (2005) J Nutr 135: 2151-2158.

Liu B, Rotenberg SA, Mirkin MV (2000) Proc Natl Acad Sci USA 97: 9855-9860.

Lowry OH, Rosenbrough NJ, Farr AL, Randall RI (1951) J Biol Chem 193: 265-275.

Mauzeroll J, Bard AJ (2004) Proc Natl Acad Sci 101: 78627867.

Mauzeroll J, Bard AJ, Owhadian O, Monks TJ (2004) Proc Natl Acad Sci 101: 17582-17587.

Nagahara N, Nishino T (1996) J Biol Chem 271: 2739527401.

Nagahara N, Katayama A (2005) J Biol Chem 280: 3456934576.

Nagahara N, Okazaki T, Nishino T (1995) J Biol Chem 270, 16230-16235.

Nandi DL, Horowitz PM, Westley J (2000) Int J Biochem Cell Biol 32: 465-473.

Niemczyk E, Majczak A, Hallmann A, Kędzior Wodniak, Woźniak M, Wakabayashi Y (2004) Acta Biochim Polon 51: 1015-1022.

Ogasawara Y, Isoda S, Tanabe S (1999) Biol Pharmaceut Bull 22: 441-445.

Ochi T (1996) Toxicology 112, 45-55.

Ponten J, Macintyre EH (1968) Acta Pathol Microbiol Scand 74: 465-86.

Poole LB, Claiborne A (1989) J Biol Chem 264: 12330-12338.

Shi MM, Iwamoto T, Forman HJ (1994) Am J Physiol 267 : L414-L421.

Skorey K, Ly HD, Kelly J, Hammond M, Ramachandran C, Huang Z, Gresser MJ, Wang Q (1997) J Biol Chem 272: 22472-22480.

Sőrbo B (1955) Methods Enzymol 2: 334-337.

Tietze F (1969) Anal Biochem 27: 502-522.

Valentine WN, Frankenfeld JK (1974) Clin Chim Acta 51: 205-210.

Wefers H, Sies H (1983) Arch Biochem Biophys 244: 568578.

Westley J (1973) Adv Enzymol Relat Area Mol Biol 39: 327368. 
Westley J (1980) In Enzymatic Basis of Detoxification II (Jakoby WB, ed) pp 245-262. Academic Press, New York,

Westley J, Adler H, Westley L, Nishida C (1983) Fundam App Toxicol 3: 377-382.

Wood IL (1987) Methods Enzymol 43: 25-29.
Wróbel M, Ubuka T, Yao WB, Abe T (1997) Physiol Chem Phys Med NMR 29: 11-14.

Wróbel M, Jurkowska H, Śliwa L, Srebro Z (2004) Toxicol Mech Meth 14: 331-337. 